\title{
Why is Life Expectancy in Busan Shorter than in Seoul? Age and Cause-Specific Contributions to the Difference in Life Expectancy between Two Cities
}

\author{
Young-Ho Khang ${ }^{1,2}$ and Jinwook Bahk ${ }^{3}$ \\ ${ }^{1}$ Department of Health Policy and Management, Seoul National University College of Medicine, Seoul; \\ ${ }^{2}$ Institute of Health Policy and Management, Seoul National University Medical Research Center, Seoul; \\ ${ }^{3}$ Department of Public Health, Keimyung University, Daegu, Korea.
}

Purpose: Seoul and Busan are the two largest cities in Korea. However, life expectancy (LE) in Busan is shorter than in Seoul and among the total Korean population. This study was conducted to decompose age- and cause-specific contributions to the LE difference between Seoul and Busan.

Materials and Methods: We obtained population and mortality data for Seoul and Busan between 2015 and 2017 from Statistics Korea. We applied Arriaga's decomposition method to life table data to estimate age- and cause-specific contributions to the LE difference between Seoul and Busan.

Results: During 2015-2017, LE in Busan was shorter than in Seoul by 2.22 years. Roughly two-thirds of the LE gap between Seoul and Busan was due to excess mortality among elderly people in Busan. The $\geq 85$ age group alone contributed to approximately $20 \%$ of the LE gap, while no meaningful contribution was made by the 1-24 age groups. Cardiovascular disease accounted for over $40 \%$ of the total LE gap between Seoul and Busan, and this factor was more prominent in women. The top 15 leading specific causes of deaths explained nearly the entire LE difference between Seoul and Busan.

Conclusion: The difference in LE between Seoul and Busan was due to higher mortality rate in Busan than in Seoul, especially in the elderly population and from cardiovascular diseases. Information on age- and cause-specific contributions to the LE difference between Seoul and Busan may guide health policy-makers to plan strategies for reducing the gap in LE.

Key Words: Cause of death, life expectancy, mortality, Republic of Korea, Seoul

\section{INTRODUCTION}

Geographical difference in health status is a public health concern, which has become an important ethical and policy issue. ${ }^{1}$ Regional differences in health in Korea have been examined between rural and urban areas ${ }^{2,3}$ or in areas with different

Received: February 8, 2019 Revised: May 9, 2019

Accepted: May 25, 2019

Corresponding author: Jinwook Bahk, PhD, Department of Public Health, Keimyung University, 1095 Dalgubeol-daero, Dalseo-gu, Daegu 42601, Korea.

Tel: 82-53-580-5190, Fax: 82-53-580-5190, E-mail: jwbahk@kmu.ac.kr

-The authors have no potential conflicts of interest to disclose.

(C) Copyright: Yonsei University College of Medicine 2019

This is an Open Access article distributed under the terms of the Creative Commons Attribution Non-Commercial License (https://creativecommons.org/licenses/ by-nc/4.0) which permits unrestricted non-commercial use, distribution, and reproduction in any medium, provided the original work is properly cited. levels of deprivation. ${ }^{4,5}$ Due to the concentration of economic, social, cultural, and healthcare resources in the capital city Seoul in Korea, differences between Seoul and other parts of Korea, in terms of wide range of indicators for well-being, have been suggested. ${ }^{6-8}$

Seoul and Busan are the two largest cities in Korea. Although Seoul is considered to be wealthier than Busan according to indicators such as the per capita gross regional domestic product, the two cities share similar total fertility rate, unemployment rate, and healthcare resources (Supplementary Table 1, only online). ${ }^{9}$ One important difference between the two cities is that life expectancy (LE) in Busan is shorter compared to Seoul. Prior investigations revealed worse indicators related to mortality levels in Busan compared to Seoul. ${ }^{5,10}$ As shown in Supplementary Table 2 (only online), more than 2-year shortfalls have been recorded in Busan compared to Seoul between 
2005 and 2017. ${ }^{11}$ The pattern held true for men and women. LE in Busan has also been lower than among the total Korean population since 2005, with a nearly 1-year disadvantage compared to the total Korean population observed among men and women in Busan (Supplementary Table 2, only online). According to data from the Korea Statistical Information Service on provincial LEs, Busan, along with South Gyeongsang province and North Chungcheong province, recorded the lowest LE in 2017 among 17 provinces in Korea. ${ }^{11}$

Such low LE in Busan has regularly drawn media attention. ${ }^{12-17}$ Since Statistics Korea has released LE information at the provincial level, the unexpectedly low LE in Busan has been highlighted in newspapers, especially in Busan. ${ }^{13-15,17}$ For example, in 2012, Busan-ilbo, a major newspaper in Busan, dealt with the health status of Busan and public health infrastructure in a series of 20 articles. ${ }^{17}$ In the media, several factors have been suggested as the causes of low LE and high mortality in Busan, including unhealthy lifestyles, ${ }^{12}$ low income and air pollution, ${ }^{15}$ high prevalence of chronic diseases, ${ }^{13}$ and poor regional public healthcare system. ${ }^{16,17}$

One approach to deciphering the causes of lower LE in Busan is to decompose the age- and cause-specific contributions to the LE disadvantage in Busan. Such decomposition allows us to quantify the magnitude of the contributions made by each age group and cause of death leading to the LE difference between Seoul and Busan. Based on such quantifications, meaningful information on risk factors associated with age at death and causes of death might be obtained. Therefore, this study was conducted to decompose age- and causespecific contributions to the LE difference between Seoul and Busan.

\section{MATERIALS AND METHODS}

\section{Data}

This study was approved by the Seoul National University Hospital Institutional Review Board (IRB No. E-1810-008975). We only used publicly available secondary data without any personal identifiers. We obtained population and mortality data for Seoul and Busan between 2015 and 2017 from Statistics Korea. Population and mortality data included the numbers of mid-year population and deaths according to sex and age groups $(0,1-4,5-9,10-14, \ldots, 80-84, \geq 85)$. A total of 29442594 subjects and 129509 deaths were analyzed for Seoul, while 10392063 subjects and 63310 deaths were examined for Busan (Supplementary Table 3, only online). Considering the small numbers of deaths among the 1-4, 5-9, and 10-15 age groups, 3-year data were combined to examine LE and agespecific contributions to the LE gap between Seoul and Busan. Mortality data were also aggregated by causes of death, which were coded according to the International Classification of Diseases, 10th Revision (ICD-10).

\section{Statistical analysis}

We calculated LE at birth for men and women in Seoul and Busan, constructing life tables using 5-year probabilities of death (Table 1). We applied Arriaga's decomposition method to the life table data to estimate age- and cause-specific contributions to the LE difference between Seoul and Busan. ${ }^{18,19}$ The results of LE decomposition according to different methods were found to be similar. ${ }^{20}$ Prior Korean studies used this method to examine age- and cause-specific contributions to LE differences by calendar year, ${ }^{21}$ sex $^{22}$ education, ${ }^{23}$ income, ${ }^{24,25}$ and country. ${ }^{26}$ This decomposition method estimates the contribution of mortality differences in each age group and cause of death to the total difference in LE at birth. The sum of the causespecific contributions to the difference in LE for a given age is equal to the total contribution for that age group, and the total differences in LE between Seoul and Busan were considered to be the sum of age- and cause-specific components. In this study, positive age-specific and cause-specific contributions referred to absolute-year contributions (e.g., 0.4 years) to the LE difference between Seoul and Busan (i.e. LE in Seoul minus LE in Busan) due to the higher mortality rates in Busan across age groups and causes of death compared to Seoul. Negative contributions referred to the reverse pattern. We presented the 5-year age group-specific contributions to the LE gap between Busan and Seoul in Fig. 1 and Supplementary Table 4 (only online). Regarding the cause-specific contributions, we first categorized causes of death into 15 broad groups (Fig. 2 and Supplementary Table 5, only online). Then, we also examined cause-specific contributions to the LE gap according to 60 detailed causes (Fig. 3 and Supplementary Table 6, only online). The classification schemes were based on previous report. ${ }^{27}$

\section{RESULTS}

Table 1 presents LE at birth by sex for the years 2015-2017 combined in Busan and Seoul. In men, Seoul had a greater LE compared to Busan by 2.49 years. The LE gap in women was slightly smaller than that in men (a 1.83-year difference). Overall, Busan citizens had shorter LE than Seoul citizens by 2.22 years.

Fig. 1 and Supplementary Table 4 (only online) show agespecific contributions to the LE difference between Busan and Seoul due to excess mortality in Busan. Except for ages 1-4, all age groups positively contributed to the LE gap between Seoul and Busan among men and women combined

Table 1. Life Expectancy at Birth in Seoul and Busan by Sex in 20152017 Combined

\begin{tabular}{lccc}
\hline & Seoul & Busan & Difference \\
\hline Overall & 84.15 & 81.93 & 2.22 \\
Men & 81.09 & 78.60 & 2.49 \\
Women & 86.69 & 84.86 & 1.83 \\
\hline
\end{tabular}




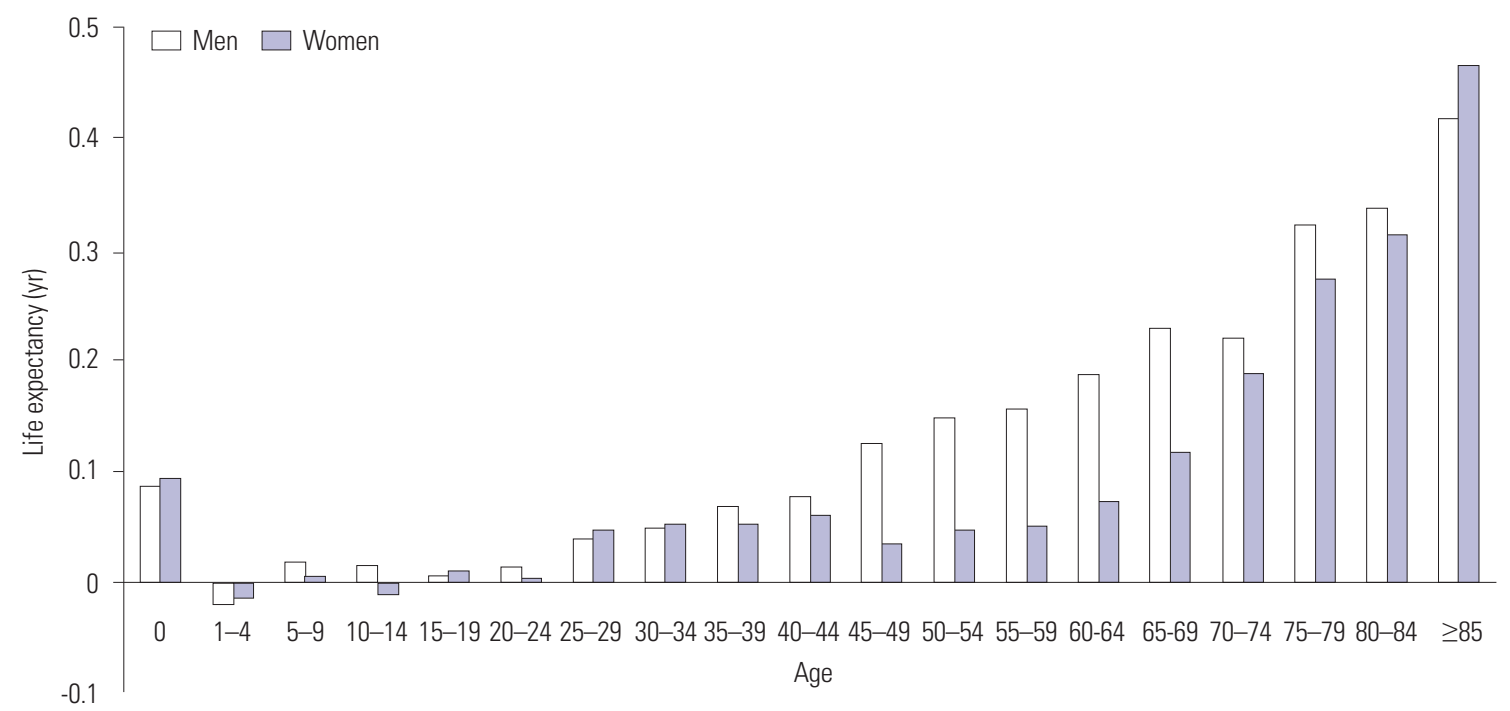

Fig. 1. Age-specific contributions to the life expectancy difference between Seoul and Busan by sex in 2015-2017 combined.
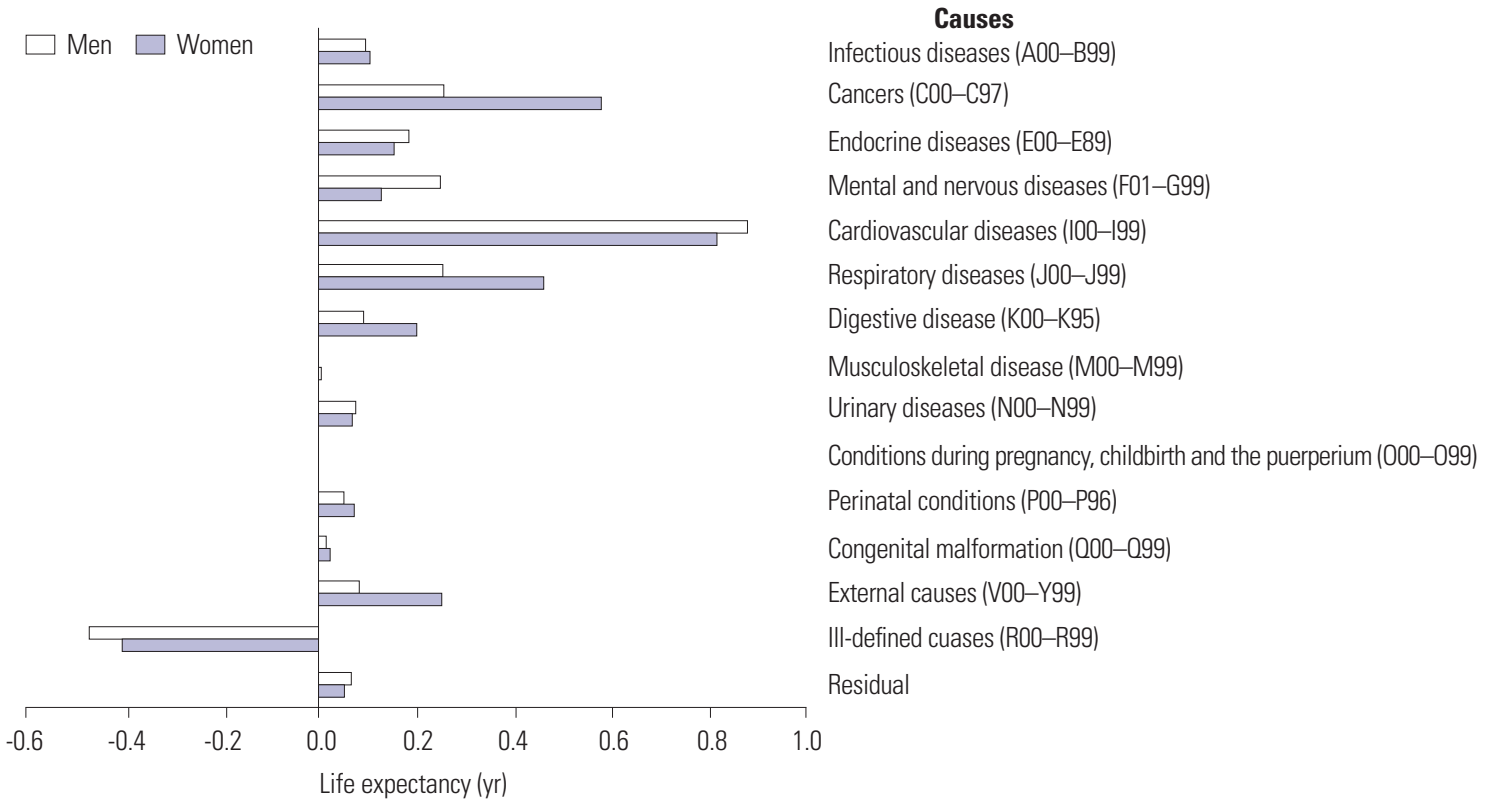

Fig. 2. Broad cause-specific contributions to the life expectancy difference between Seoul and Busan by sex in 2015-2017 combined.

(Supplementary Table 4, only online). In women, due to the small numbers of deaths among ages $1-4(n=11), 5^{-9}(n=13)$, and $10-14(\mathrm{n}=6)$ in Busan, unstable patterns in age-specific contributions were noticed. Fig. 1 also shows increasing agespecific contributions with age, especially in men. The contribution made by elderly people aged $\geq 65$ was 1.47 years, accounting for $66.2 \%$ of the total LE gap (2.22 years) in men and women combined. The corresponding figures for men and women were 1.53 years in men $(61.4 \%$ of the total LE gap in men) and 1.35 years in women (73.7\% of the total LE gap in women). In men and women, the largest age-specific contribution was made by the $\geq 85$ age group: 0.48 years in men and women combined, 0.42 years in men, and 0.47 years in women. This contribution by the $\geq 85$ age group accounted for $21.5 \%$ of the total LE gap between Seoul and Busan in men and women combined, $16.8 \%$ in men, and $25.4 \%$ in women.

Fig. 2 and Supplementary Table 5 (only online) present 15 broad cause-specific contributions to the LE difference. Of the 15 broad causes of death, positive contributions to the LE gap were found for 14 causes among men and women, with the exception of ill-defined causes (ICD-10 code: R00-R99). The largest positive contribution was made by cardiovascular diseases (I00-I99) in both men and women: 0.94 years in men and women combined, 0.81 years in men, and 0.88 years in women. This contribution by cardiovascular diseases accounted for $42.1 \%$ of the total LE gap between Seoul and Busan in men and women combined, $32.7 \%$ in men, and $48.0 \%$ in women. In men, contributions by cancers (C00-C97), respira- 


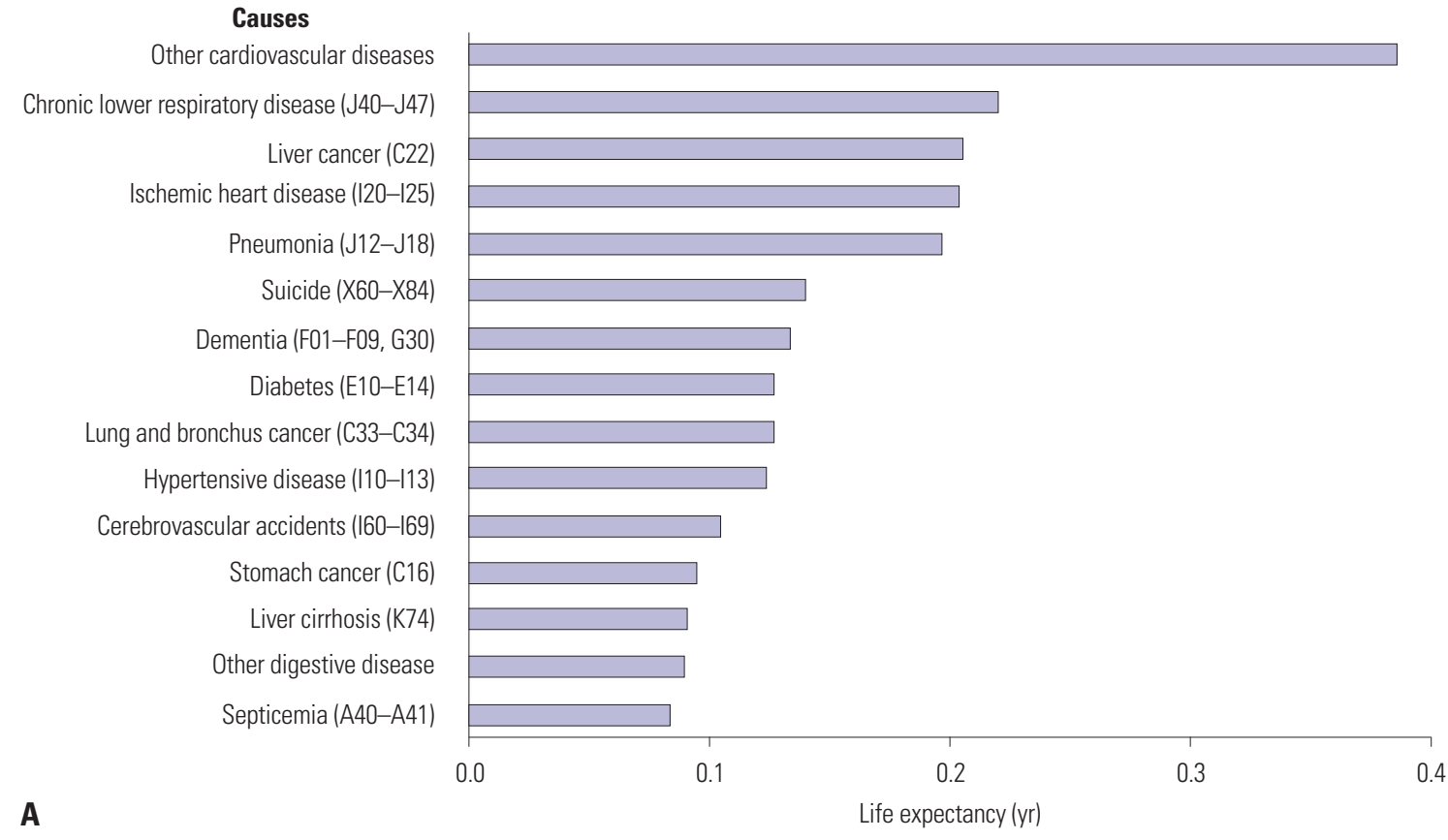

Causes

Other cardiovascular diseases

Dementia (F01-F09, G30)

Ischemic heart disease (I20-I25)

Hypertensive disease (I10-I13)

Diabetes (E10-E14)

Chronic lower respiratory disease (J40-J47)

Cerebrovascular accidents (I60-169)

Pneumonia (J12-J18)

Septicemia (A40-A41)

Liver cancer (C22)

Other urinary disease

Biliary tract/gall bladder cancer (C23-C24)

Suicide (X60-X84)

Other digestive disease

Perinatal conditions (P00-P96)

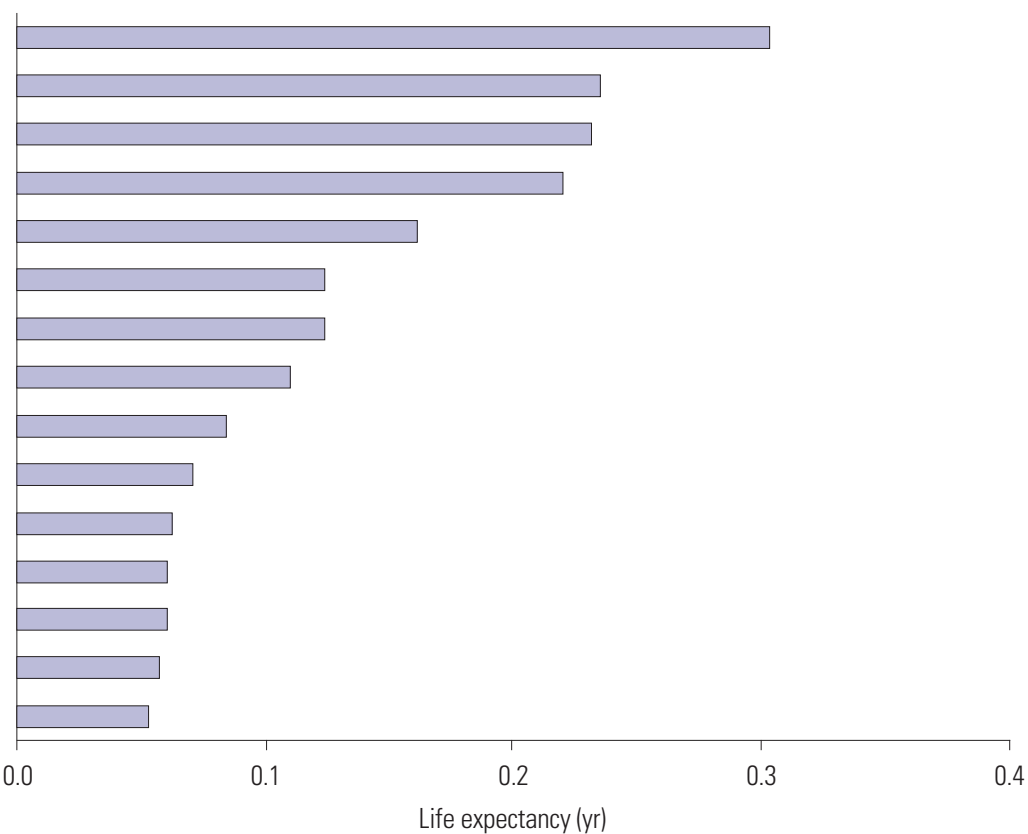

B

Life expectancy (yr)

Fig. 3. Detailed cause-specific contributions to the life expectancy difference between Seoul and Busan by sex (A: men, B: women).

tory diseases (J00-J99), and external causes (V00-Y99) were especially significant. These four broad causes (cardiovascular diseases, cancer, respiratory diseases, and external causes) together contributed positively to 2.10 years $(94.3 \%)$ of the LE gap in men. In women, in addition to cardiovascular diseases, significant contributors to the LE gap included cancers, endocrine diseases (E00-E89), mental and nervous diseases (F01G99), and respiratory diseases. Meanwhile, contributions by musculoskeletal disease (M00-M99), conditions during pregnancy, childbirth and puerperium (O00-O99), and congenital malformations (Q00-Q99) were minimal in both men and women.

Fig. 3 shows cause-specific contributions to the LE gap between Seoul and Busan for the top 15 leading causes in terms of the absolute magnitude of the contribution, which was derived from an analysis of cause-specific contributions to the LE gap according to 60 detailed causes of death (Supplementary Table 6, only online). Combined contributions of the top 15 causes to the LE gap were 2.31 years in men and 1.95 years in women, corresponding to $93.0 \%$ of total LE gap in men and 
$106.4 \%$ of the total LE gap in women. The cause of death that contributed most to the LE gap was other cardiovascular diseases in both men and women. However, differences were found between men and women in the ranking of causes of death contributing to the LE gap. In men, chronic lower respiratory disease (J40-J47) and liver disease (C22) were relatively important, while dementia (F01-F09, G30) and hypertensive diseases (I10-I13) were among the top causes in women. Lung and bronchus cancer (C33-C34), stomach cancer (C16), and liver cirrhosis (K74) were among the top 15 causes only in men, while other urinary diseases, biliary tract/gall bladder cancer (C23-C24), and perinatal conditions (P00-P96) were among the top 15 causes only in women.

\section{DISCUSSION}

The results of this study indicated that LE for the years 20152017 in Busan was shorter compared to Seoul by 2.22 years. The magnitude of this disadvantage in Busan is considerable. Given that a 4.5-year increase in LE was achieved in the 12year period between 2005 and 2017 among the entire Korean population (Supplementary Table 2, only online), the 2.22year difference in LE between Seoul and Busan corresponds to roughly a 6-calendar-year difference in LE in Korea. In addition, according to the data from the Korea Statistical Information Service, a 3.78-year gain in LE would be expected in 2017 if all cancer deaths were eliminated in Korea. ${ }^{28}$ A 2.22year gain in LE would be anticipated when deaths from stomach cancer, liver cancer, colon cancer, and lung cancer were eliminated from the Korean population in $2017 .^{28}$

This study also showed that roughly two-thirds of the LE gap between Seoul and Busan was due to excess mortality among elderly people in Busan. The $\geq 85$ age group alone contributed to $20 \%$ of the LE gap, while no meaningful contributions were made by the 1-24 age groups. These results highlight the importance of excess mortality among the elderly, especially among the oldest age group in Busan. Prior LE decomposition studies in Korea on the increase in LE with time, ${ }^{21}$ socioeconomic inequalities in $\mathrm{LE}^{25}$ and gender inequality in $\mathrm{LE}^{22}$ showed that major differences in LE were caused by mortality differences among middle-aged adults and the early elderly population. Contributions of the oldest old were not large in those studies. $^{21,22,25}$ Several explanations for these discrepancies should be considered. Healthcare services and end-of-life care for the elder population and the oldest old should be examined. Differences in public attitudes toward deaths among the oldest old should also be explored. In addition, the possibility of selective migration prior to death (i.e., moving to Busan at the end of one's life) and the effect of adverse experiences accumulated throughout the life course ${ }^{29}$ should be also considered.

The results of our analysis of broad cause-specific contribu- tions revealed that over $40 \%$ of the LE gap between Seoul and Busan was due to excess mortality from cardiovascular diseases in Busan, especially among those aged $\geq 65$ (Supplementary Table 7, only online). Some of this contribution might have been due to higher prevalence rates of unhealthy behaviors in Busan, including current smoking, alcohol consumption, highrisk alcohol use, and not engaging in walking as physical activity, compared to Seoul..$^{30}$ Contribution of cardiovascular diseases was more prominent in women. The high level of cardiovascular mortality in Busan compared to other provinces has been suggested to be an explanation of the high overall mortality rate in Busan. ${ }^{5,13}$ However, no previous study has quantified the extent of contribution of cardiovascular disease to the LE gap between Seoul and Busan. In men, among broad causes, cancers, respiratory diseases, and external causes played an important role in explaining the high mortality rate in Busan.

This study also identified 15 leading specific causes of death that contributed most to the LE difference between Seoul and Busan. These 15 leading causes of death explained nearly all of the LE gap between Seoul and Busan (93.0\% in men and 106.4\% in women). Our calculation also showed that the 10 leading causes explained $74.6 \%$ of the LE gap in men and $90.5 \%$ of the LE gap in women, respectively. These results suggest the possibility of reducing the LE gap by addressing excess mortality from each leading cause of death in Busan. In both men and women, other cardiovascular diseases, ischemic heart disease, hypertensive disease, and cerebrovascular accidents were among the 15 leading causes of death contributing to the LE gap, which again highlights the importance of cardiovascular disease in explaining the LE disadvantage in Busan compared with Seoul. ${ }^{5,13}$ In contrast to the findings in women, in men, chronic lower respiratory disease and liver disease were the second and third causes of death, respectively, and lung and bronchus cancer, stomach cancer, and liver cirrhosis were among the 15 leading causes of death contributing to the LE gap in men. Cigarette smoking, ${ }^{31}$ alcohol consumption, ${ }^{32} \mathrm{Clo}$ norchis sinensis infection, ${ }^{33,34}$ and hepatitis $\mathrm{B}$ and $\mathrm{C}$ infections $s^{35,36}$ should be considered as explanations for these findings among men in Busan.

This study was limited in its ability to provide more direct information on the cause of the LE disadvantage in Busan compared to Seoul. However, the results of this age- and cause-specific analysis may guide further explorations of downstream causes (e.g., health-related behaviors, occurrence and treatment of chronic diseases, or access to medical treatment) of the LE disadvantage. In addition, our quantification of the contribution of each age group and cause to the LE gap could be an important item to consider in planning strategies to reduce the age- and cause-specific mortality rate in Busan.

In conclusion, this study quantified age- and cause-specific contributions to the LE difference between Seoul and Busan. The 2.22-year difference in LE for the years 2015-2017 be- 
tween Seoul and Busan was mainly due to excess mortality in the elderly population and from cardiovascular diseases. Those aged $\geq 65$ accounted for two-thirds of the LE gap, while over $40 \%$ of the LE gap was due to cardiovascular diseases. The top 15 leading specific causes of deaths explained nearly all of the LE gap between Seoul and Busan. Information on age- and cause-specific contributions to the LE difference between Seoul and Busan may guide health policy-makers in planning strategies to reduce the gap in LE. This study shows that the mortality disparity between Busan (second largest metropolitan city in Korea) and Seoul (capital city) exist in almost all age groups. Typically, regional health disparities have tended to be explained in the frame of the gap between urban and rural areas. However, especially in the Korean context, the gap between capital and non-capital regions is also important as well as between urban and rural areas.

\section{ACKNOWLEDGEMENTS}

This research was supported by a grant of the Korea Health Technology R\&D Project through the Korea Health Industry Development Institute (KHIDI), funded by the Ministry of Health \&Welfare, Republic of Korea (grant number: HI18C0446).

\section{AUTHOR CONTRIBUTIONS}

Conceptualization: Khang YH. Data curation: Bahk J. Formal analysis: Bahk J. Writing_original draft: Khang YH. Writing—review \& editing: Khang YH and Bahk J.

\section{ORCID iDs}

Young-Ho Khang https://orcid.org/0000-0002-9585-8266

Jinwook Bahk https://orcid.org/0000-0002-7715-9955

\section{REFERENCES}

1. Duncan DT, Kawachi I. Neighborhoods and Health. 2nd ed. Oxford: Oxford University Press; 2018.

2. Lim S, Jang HC, Lee HK, Kimm KC, Park C, Cho NH. A rural-urban comparison of the characteristics of the metabolic syndrome by gender in Korea: the Korean Health and Genome Study (KHGS). J Endocrinol Invest 2006;29:313-9.

3. Bahk J, Khang YH. Trends in childhood obesity and central adiposity between 1998-2001 and 2010-2012 according to household income and urbanity in Korea. BMC Public Health 2016;16:18.

4. Lee J, Lee WY, Noh M, Khang YH. Does a geographical context of deprivation affect differences in injury mortality? A multilevel analysis in South Korean adults residing in metropolitan cities. J Epidemiol Community Health 2014;68:457-65.

5. Choi MH, Cheong KS, Cho BM, Hwang IK, Kim CH, Kim MH, et al. Deprivation and mortality at the town level in Busan, Korea: an ecological study. J Prev Med Public Health 2011;44:242-8.

6. Kim IK. Socioeconomic Concentration in the Seoul metropolitan area and its implications in the urbanization process of Korea. Korean J Sociol 2010;44:111-28.

7. Lee SW, Park K, Kang HS, Ryu JS, Shin H, Kim JC, et al. Develop- ment gap between the capital regions and the non-capital region in Korea. 1st ed. Seoul: Hanul Academy; 2002.

8. Kim JH, Kim SY, Yun SJ, Chung JI, Choi H, Yu HS, et al. Medical travel among non-Seoul residents to seek prostate cancer treatment in medical facilities of Seoul. Cancer Res Treat 2019;51:53-64.

9. Korean Statistical Information Service (KOSIS). Provincial indicators [Internet]. Daejeon: KOSIS; c2018 [accessed on 2018 December 10]. Available at: http://kosis.kr/visual/eRegionJipyo/index/ index.do.

10. Byun YC, Lee SK, Park SJ, Lee MK. Regional differences in health expectancy in Korea and policy suggestions. Seoul: Korea Institute for Health and Social Affairs; 2011.

11. Korean Statistical Information Service (KOSIS). Life expectancy 17 provinces in Korea [Internet]. Daejeon: KOSIS; c2018 [accessed on 2018 December 10]. Available at: http://kosis.kr/statisticsList/ statisticsListIndex.do?menuId=M_01_01\&vwcd=MT_ZTITLE\&p armTabId=M_01_01\#SelectStatsBoxDiv.

12. Kang DS. Which city has the lowest life expectancy in Korea? Nocut News. 2010 October 14. [accessed on 2018 December 11]. Available at: http://www.nocutnews.co.kr/news/763098.

13. Kim JW. Life expectancy in Busan of 78.8 years: the lowest level in Korea. Busan-ilbo. 2009 December 10. [accessed on 2018 December 11]. Available at: http://news20.busan.com/controller/newsController.jsp?newsId=20091210000114.

14. Kim JW. Life expectancy in Busan of 80.2 years. The lowest level in Korea. Busan-ilbo. 2012 December 5. [accessed on 2018 December 11]. Available at: http://news20.busan.com/controller/newsController.jsp?newsId=20121205000126.

15. Choi SH. Life expectancy in Busan of 81.6 years: 6th in 7 metropolitan cities in Korea. Kookje Sinmun. 2015 December 3. [accessed on 2018 December 11]. Available at: http://www.kookje. co.kr/news2011/asp/newsbody.asp? code $=0300 \& k e y=20151203$. 99002132513.

16. Gil JS. Longer illness and shorter life expectancy in Busan and Gyeongnam. KNN. 2018 October 12. [accessed on 2018 December 11]. Available at: http://www.knn.co.kr/176071.

17. Kim KH. Busan with the worst health status. Let's change public healthcare in Busan. Busan-ilbo. 2013 December 4. [accessed on 2018 December 28]. Available at: http://www.journalist.or.kr/news/ article.html?no=32394.

18. Arriaga EE. Measuring and explaining the change in life expectancies. Demography 1984;21:83-96.

19. Auger N, Feuillet P, Martel S, Lo E, Barry AD, Harper S. Mortality inequality in populations with equal life expectancy: Arriaga's decomposition method in SAS, Stata, and Excel. Ann Epidemiol 2014; 24:575-80.

20. Ponnapalli KM. A comparison of different methods for decomposition of changes in expectation of life at birth and differentials in life expectancy at birth. Demogr Res 2005;12:141-72.

21. Yang S, Khang YH, Harper S, Davey Smith G, Leon DA, Lynch J. Understanding the rapid increase in life expectancy in South Korea. Am J Public Health 2010;100:896-903.

22. Yang S, Khang YH, Chun H, Harper S, Lynch J. The changing gender differences in life expectancy in Korea 1970-2005. Soc Sci Med 2012;75:1280-7.

23. Jung-Choi K, Khang YH, Cho HJ, Yun SC. Decomposition of educational differences in life expectancy by age and causes of death among South Korean adults. BMC Public Health 2014;14:560.

24. Khang YH, Yang S, Cho HJ, Jung-Choi K, Yun SC. Decomposition of socio-economic differences in life expectancy at birth by age and cause of death among 4 million South Korean public servants and their dependents. Int J Epidemiol 2010;39:1656-66.

25. Khang YH, Bahk J, Yi N, Yun SC. Age- and cause-specific contribu- 
tions to income difference in life expectancy at birth: findings from nationally representative data on one million South Koreans. Eur J Public Health 2016;26:242-8.

26. Bahk J, Ezzati M, Khang YH. The life expectancy gap between North and South Korea from 1993 to 2008. Eur J Public Health 2018;28: 830-5.

27. Khang YH, Yun SC, Bahk J, Kang HY, Kim I, Seo S, et al. Developing indicators for evaluating and monitoring the health plan 2020 using the National Health Information Database of the National Health Insurance Service in Korea [Internet]. Wonju: National Health Insurance Service; c2017 [accessed on 2018 December 10]. Available at: http://www.nhis.or.kr/bbs7/boards/B0069/22655?boardKe $\mathrm{y}=39$ \&boardName $=$ B0069.

28. Korean Statistical Information Service (KOSIS). Gains in life expectancy after eliminating causes of death [Internet]. Daejeon: KOSIS; c2018 [accessed on 2018 December 10]. Available at: http:// kosis.kr/statisticsList/statisticsListIndex.do?menuId= M_01_01\& vwcd=MT_ZTITLE\&parmTabId=M_01_01\#SelectStatsBoxDiv.

29. Karanikolos M, Leon DA, Smith PC, McKee M. Minding the gap: changes in life expectancy in the Baltic States compared with Finland. J Epidemiol Community Health 2012;66:1043-9.

30. Kang YW, Ko YS, Kim KY, Sung C, Lee DH, Jeong E. Trends in health-related behaviors of Korean adults: study based on data from the 2008-2014 Community Health Surveys. Epidemiol Health 2015;37:e2015042.

31. Jee SH, Samet JM, Ohrr H, Kim JH, Kim IS. Smoking and cancer risk in Korean men and women. Cancer Causes Control 2004;15:341-8.

32. Jee SH, Ohrr H, Sull JW, Samet JM. Cigarette smoking, alcohol drinking, hepatitis B, and risk for hepatocellular carcinoma in Korea. J Natl Cancer Inst 2004;96:1851-6.

33. Song SB. Epidemiological studies of Clonorchis sinensis in lower area of Nag Dong river nearby Busan City in Korea. Korean J Parasitol 1982;20:133-41.

34. Kim BJ, Ock MS, Kim IS, Yeo UB. Infection status of Clonorchis sinensis in residents of Hamyang-gun, Gyeongsangnam-do, Korea. Korean J Parasitol 2002;40:191-3.

35. Ju YH, Shin HR, Oh JK, Kim DI, Lee DH, Kim BK, et al. A seroepidemiological study of hepatitis B and C virus (HBV and HCV) infections in the young population in parts of Busan, Korea. J Prev Med Public Health 2004;37:253-9.

36. Shon HS, Choi HY, Kim JR, Ryu SY, Lee YJ, Lee MJ, et al. Comparison and analysis of the prevalence of hepatitis $\mathrm{C}$ virus infection by region in the Republic of Korea during 2005-2012. Clin Mol Hepatol 2015;21:249-56. 